\title{
Primary Failure of Eruption: A Cause of Posterior Open Bite
}

\author{
Ganiga C Shivakumar ${ }^{1}$, Adit Srivastava ${ }^{2}$, Sahana Shivakumar ${ }^{3}$
}

\begin{abstract}
Primary eruption failure is a poorly understood condition in which the teeth fail to erupt in oral cavity in absence of any local or systemic factors. First and second molars are most commonly affected but one or more number of teeth, primary or permanent can be partially or completely affected. The orthodontic or surgical methods to get such teeth in occlusion have failed miserably. The early diagnosis of primary eruption failure (PEF) will allow the dentist to accurately rehabilitate the patient without wasting any time on treatments which are bound to fail.
\end{abstract}

Keywords: Anterior deep bite, Posterior open bite, Primary eruption failure, Retained deciduous teeth.

International Journal of Clinical Pediatric Dentistry (2019): 10.5005/jp-journals-10005-1646

\section{INTRODUCTION}

Normal eruption of teeth is of prime concern to the dentist as it affects the overall growth of maxillofacial structures. Eruption failure can be due to mechanical obstruction (which can be idiopathic or pathogenic), various environmental or genetic factors, or disruption of the eruption itself. Various pathologies such as cysts, other teeth, bone, and fibrous gingival can lead to a tooth not getting erupt in the oral cavity. The primary failure eruption (PFE) was first described by Proffit and Vig, in which nonankylosed teeth fail to erupt owing to malfunction of the eruption mechanism. The involved teeth erupt partially and then cease to erupt becoming submerged but not ankylosed. Mostly posterior teeth are affected, leading to a posterior open bite. ${ }^{1}$ The disease is commonly seen unilaterally but bilateral involvement has also been reported. The tooth affected by PFE is likely to become ankylosed when force is applied. The cause of PFE is still not clear, but genetic predisposition is often implicated. A definite diagnosis is not direct as it incorporates both primary and secondary retention; usually a diagnosis of PFE is made only when initial treatment modalities have failed. ${ }^{2}$ We hereby present a case of primary failure of eruption in which orthodontic treatment was planned.

\section{Case Description}

A 17-year-old male patient was referred to the department by a private practitioner with the complaint of inability to chew from one side (Fig. 1). The practitioner wanted to correct his bite by orthodontic treatment and sent the patient to us for evaluation before starting the case. The clinical examination revealed a right-side posterior open bite (Fig. 2) with an anterior deep bite (Fig. 3), and multiple submerged teeth and retained 53, 54, 55 and 84 . An orthopantomogram was advised, which showed submerged permanent molars and premolars on the right side in both maxillary and mandibular arches without any evidence of ankylosis (Fig. 4). Mechanical obstruction due to retained deciduous teeth was seen in relation to $53,54,55$, and 84 region. After ruling out, local, systemic, and hormonal factors and considering the failure of eruption of the posterior teeth distal to the most mesially affected teeth, a diagnosis of PFE was made. The disorder was explained to the patient and the treating clinician. The orthodontic treatment was abandoned. The patient was advised to get the posterior open bite corrected prosthodontically with the help of crowns.
${ }^{1}$ Department of Oral Medicine and Radiology, Babu Banarasi Das College of Dental Sciences, Lucknow, Uttar Pradesh, India

${ }^{2}$ Department of Oral Medicine and Radiology, Faculty of Dental Sciences, Institute of Medical Sciences, Banaras Hindu University, Varanasi, Uttar Pradesh, India

${ }^{3}$ Department of Public Health Dentistry, Babu Banarasi Das College of Dental Sciences, Lucknow, Uttar Pradesh, India

Corresponding Author: Adit Srivastava, Department of Oral Medicine and Radiology, Faculty of Dental Sciences, Institute of Medical Sciences, Banaras Hindu University, Varanasi, Uttar Pradesh, India, Phone: +91 9451525522, e-mail: dr.adit69@gmail.com

How to cite this article: Shivakumar GC, Srivastava A, et al. Primary Failure of Eruption: A Cause of Posterior Open Bite. Int J Clin Pediatr Dent 2019;12(4):360-361.

Source of support: Nil

Conflict of interest: None

\section{Discussion}

The prevalence of PFE is extremely low at about $0.06 \% .^{3}$ The etiology of PFE is not known. Genetic factors such as mutations

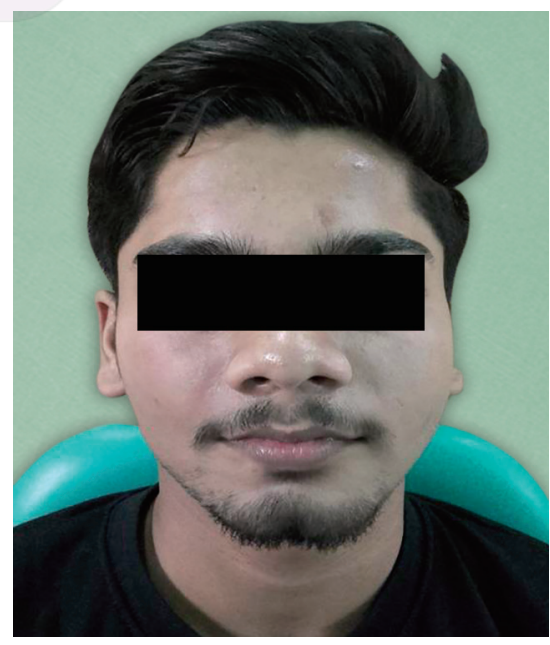

Fig. 1: Front profile of the patient

o The Author(s). 2019 Open Access This article is distributed under the terms of the Creative Commons Attribution 4.0 International License (https://creativecommons. org/licenses/by-nc/4.0/), which permits unrestricted use, distribution, and non-commercial reproduction in any medium, provided you give appropriate credit to the original author(s) and the source, provide a link to the Creative Commons license, and indicate if changes were made. The Creative Commons Public Domain Dedication waiver (http://creativecommons.org/publicdomain/zero/1.0/) applies to the data made available in this article, unless otherwise stated. 


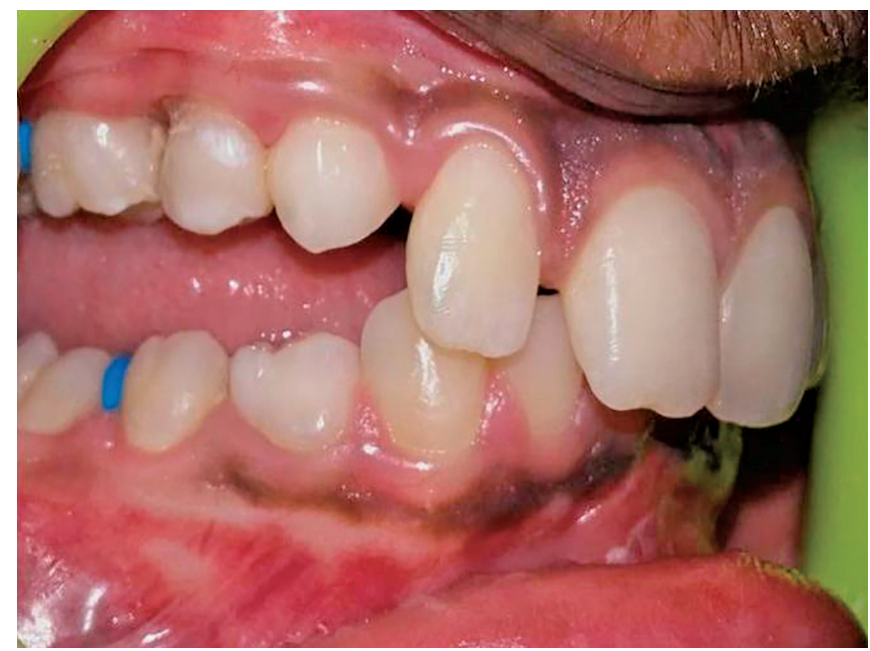

Fig. 2: Right side posterior open bite

in parathyroid hormone receptor 1 (PTH 1R) have often been implicated. Usually in such cases, the familial history may help in diagnosing the case, but in our case, no such familial history was reported. Diagnosis of PFE should always be made after ruling out mechanical failure of eruption (MFE), which may be due to retained deciduous teeth, supernumerary teeth, or fibrous gingiva. ${ }^{4}$ A key distinguishing feature between PFE and MFE is whether distal teeth are normal or affected. ${ }^{1}$ If distal teeth are affected, a diagnosis of PFE is made as was in our case. PFE affects the posterior dentition and is usually unilateral, but bilateral involvement is also reported and can affect either of the jaws, namely maxilla and mandible. The findings in our present case were in agreement with those of the Profit and Vig as well as Sofia et al., posterior dentition is most commonly affected. ${ }^{5}$ PFE may be of two types, one with total eruption failure ${ }^{6}$ and the second one with a slight eruption ceasing to erupt thereafter, which is called as secondary retention. Our case showed the secondary retention of PFE. Differential diagnosis of PFE may include cleidocranial dysplasia, osteopetrosis, and Rutherford syndrome, which have similar features as those of PFE. ${ }^{1}$

The management of PFE is very limited. Teeth with PFE are unresponsive to orthodontic force and ankylose when subjected to it. Prosthetic correction is the only viable treatment in such patients. ${ }^{1}$ Our patient was also advised to achieve occlusion through crown restoration. Surgical procedures such as distraction osteogenesis or segmental osteotomy have also been done in similar cases, but their use in routine practice is often limited owing to complication associated with such procedures. ${ }^{7}$

\section{Conclusion}

PFE is a rare disease in which nonankylosed teeth fail to erupt in the oral cavity in the absence of mechanical obstruction, resulting in posterior open bite. Diagnosis of PFE is difficult owing to its rare occurrence. The conventional orthodontic treatment is bound to fail as they result in ankylosis of the tooth. The situation should be explained to the patient and prosthetic or surgical correction should be provided. Dental surgeons encounter patients with noneruption of teeth quite often. This case highlights a possible diagnosis of PFE after all other associated etiologies have been ruled out. PFE demands a different approach to treatment when conventional

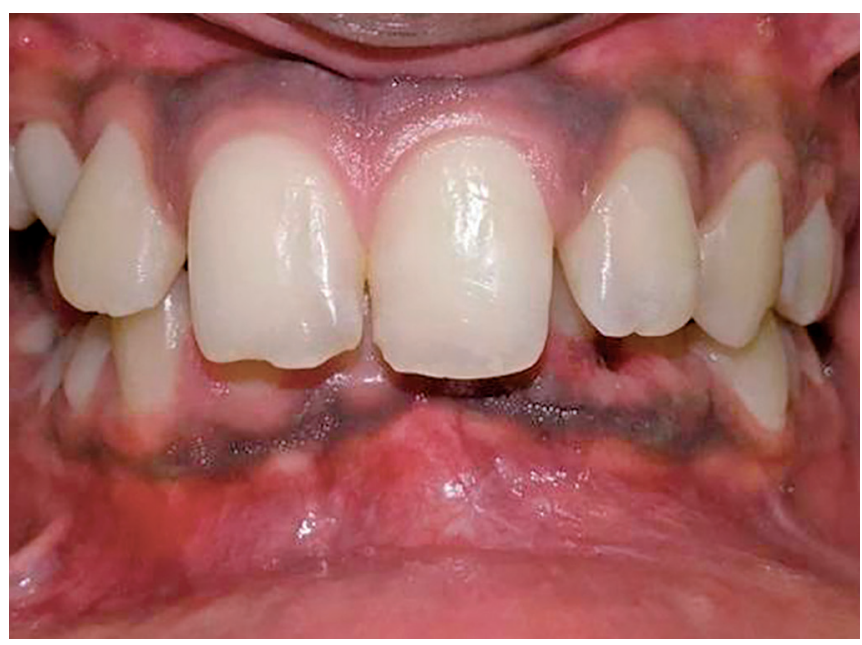

Fig. 3: Anterior deep bite

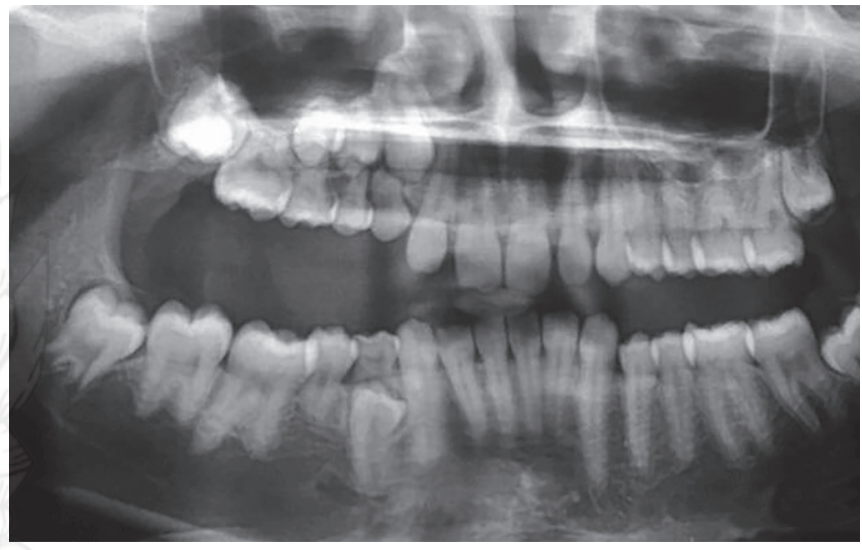

Fig. 4: Orthopantomogram

treatment modalities such as orthodontic treatment fail. Hence, the knowledge about this disorder is necessary in formulating diagnosis and planning treatment for nonerupting or submerged teeth.

\section{REFERENCES}

1. Frazier-Bowers SA, Koehler KE, et al. Primary failure of eruption: Further characterization of a rare eruption disorder. Am J Orthod Dentofacial Orthop 2007 May;131(5):578.e1-578.e11. DOI: 10.1016/ j.ajodo.2006.09.038.

2. Proffit WR, Vig KW. Primary failure of eruption: A possible cause of posterior open-bite. Am J Orthod 1981 Aug;80(2):173-190. DOI: 10.1016/0002-9416(81)90217-7.

3. Vijesh PK, Arun Kumar BR, et al. Primary Eruption Failure: A Review. Int J Appl Dent Sci 2015;1(4):149-151.

4. Jain U, Kallury A, et al. Primary failure of eruption (PFE). BMJ Case Rep 2015;2015:bcr2015209703. DOI: 10.1136/bcr-2015-209703.

5. Sofia A, Bister $D$, et al. The clinical features and aetiological basis of primary eruption failure. Eur J Orthod 2006 Dec;28(6):535-540. DOI: 10.1093/ejo/cjl033.

6. Raghoebar GM, Boering G, et al. Eruption disturbances of permanent molars: a review. J Oral Pathol Med 1991 Apr;20(4):159-166. DOI: 10.1111/j.1600-0714.1991.tb00913.x.

7. Raghoebar GM, Boering G, et al. Clinical, Radiographic And Histological Characteristics Of Secondary Retention Of Permanent Molars. J Dent 1991 Jun;19(3):164-170. DOI: 10.1016/03005712(91)90007-I. 